\title{
Conditional Requirement for Exopolysaccharide in the Mesorhizobium-Lotus Symbiosis
}

\author{
Simon J. Kelly, ${ }^{1,2}$ Artur Muszyński, ${ }^{3}$ Yasuyuki Kawaharada, ${ }^{2,4}$ Andree M. Hubber, ${ }^{1}$ John T. Sullivan, ${ }^{1,2}$ \\ Niels Sandal, ${ }^{2,4}$ Russell W. Carlson, ${ }^{3}$ Jens Stougaard, ${ }^{2,4}$ and Clive W. Ronson ${ }^{1,2}$ \\ ${ }^{1}$ Department of Microbiology and Immunology, University of Otago, Dunedin, New Zealand; ${ }^{2}$ Centre for Carbohydrate \\ Recognition and Signalling, Aarhus University, Aarhus, Denmark; ${ }^{3}$ Complex Carbohydrate Research Center, University \\ of Georgia, Athens, U.S.A.; ${ }^{4}$ Department of Molecular Biology and Genetics, Aarhus University
}

Submitted 19 September 2012. Accepted 22 October 2012.

\begin{abstract}
Rhizobial surface polysaccharides are required for nodule formation on the roots of at least some legumes but the mechanisms by which they act are yet to be determined. As a first step to investigate the function of exopolysaccharide (EPS) in the formation of determinate nodules, we isolated Mesorhizobium loti mutants affected in various steps of EPS biosynthesis and characterized their symbiotic phenotypes on two Lotus spp. The wild-type M. loti R7A produced both high molecular weight EPS and lower molecular weight (LMW) polysaccharide fractions whereas most mutant strains produced only LMW fractions. Mutants affected in predicted early biosynthetic steps (e.g., exoB) formed nitrogen-fixing nodules on Lotus corniculatus and L. japonicus 'Gifu', whereas mutants affected in mid or late biosynthetic steps (e.g., exoU) induced uninfected nodule primordia and, occasionally, a few infected nodules following a lengthy delay. These mutants were disrupted at the stage of infection thread (IT) development. Symbiotically defective EPS and Nod factor mutants functionally complemented each other in co-inoculation experiments. The majority of full-length IT observed harbored only the EPS mutant strain and did not show bacterial release, whereas the nitrogen-fixing nodules contained both mutants. Examination of the symbiotic proficiency of the exoU mutant on various $L$. japonicus ecotypes revealed that both host and environmental factors were linked to the requirement for EPS. These results reveal a complex function for $M$. loti EPS in determinate nodule formation and suggest that EPS plays a signaling role at the stages of both IT initiation and bacterial release.
\end{abstract}

The establishment of the symbiotic interaction involving the soil bacteria collectively referred to as rhizobia and their compatible host legume species requires molecular communication between the two partners (Desbrosses and Stougaard 2011; Gage 2004; Jones et al. 2007; Oldroyd et al. 2011). Speciesspecific flavonoid compounds secreted from legume roots are

Corresponding author: C. W. Ronson; E-mail: Clive.Ronson@otago.ac.nz

Current address for A. M. Hubber: Research Institute for Microbial Diseases, Osaka University, Suita, Osaka, Japan.

* The $\boldsymbol{e}$-Xtra logo stands for "electronic extra" and indicates six supplementary figures are published online. Also, Figures 2 and 5 appear in color online.

(C) 2013 The American Phytopathological Society recognized by compatible rhizobial NodD proteins that then activate expression of genes responsible for the production of lipo-chito oligosaccharides, commonly known as Nod factors (Gage 2004; Long 1996). In root-hair-infected legumes, Nod factor signaling leads to root hair curling and to the induction of plant cortical cell division, leading to the formation of nodule primordia. Rhizobia entrapped by the root hair curl grow to form a microcolony and then enter the root hair through an infection thread (IT) that is formed by the inversion of plant cell wall growth in a process that requires the presence of viable rhizobia. The IT grows toward the nodule primordium, with the rhizobia keeping pace with the tip of the growing thread by cell division. The IT ramifies in the plant cortex and, once a branch reaches a cell in the nodule primordium, rhizobia are released into plant cells via an endocytotic process that leaves them enclosed in a membrane of plant origin termed the peribacteroid membrane. The rhizobia then differentiate into bacteroids that fix nitrogen. On plant hosts that form indeterminate nodules, cell division starts in the inner cortex and the meristem is persistent. Hence, the nodules continue to elongate through new cell division followed by infection, and all developmental stages are present as a gradient in a single nodule. In determinate nodules, meristematic activity initiates in the outer root cortex and is short lived. Nodule growth is largely by cell expansion and, hence, the nodules are spherical and developmentally homogeneous.

In addition to Nod factors, the processes of IT induction, entry, and exit are likely to require further rhizobial signal molecules. Rhizobial exopolysaccharides (EPS) have been proposed to play a number of roles during infection on at least some hosts, including passive roles such as preventing cellulose-mediated agglutination (Laus et al. 2005), through to active signaling roles in the modulation of plant defense responses (Niehaus et al. 1993; Parniske et al. 1994; Wielbo et al. 2004). Studies of rhizobial mutants suggest that EPS is required for IT initiation and elongation on some hosts (Cheng and Walker 1998; Laus et al. 2004, 2005; Pellock et al. 2000; Stuurman et al. 2000). For example, succinoglycan-deficient mutants of Sinorhizobium meliloti induce meristematic activity and root-hair curling but fail to form IT, resulting in the formation of uninfected "pseudonodules". Support for EPS functioning as a signaling molecule rather than providing a structural or protective role during IT development is largely derived from experiments that demonstrated the rescue of EPS-deficient strains by the addition of low amounts of purified EPS derived from the parent strain (Battisti et al. 1992; Djordjevic et al. 1987; Urzainqui and Walker 1992) and by the finding that a low molecular weight form comprising a small number of the repeating unit of EPS is the symbiotically 
critical form in S. meliloti (Wang et al. 1999) and Rhizobium sp. strain NGR234 (Staehelin et al. 2006).

Although EPS production is ubiquitous among rhizobia, the composition of EPS produced by differing species varies widely (Skorupska et al. 2006). The synthesis and role of EPS has been most extensively studied for $S$. meliloti, and a biosynthetic pathway for succinoglycan (EPS I) (Supplementary Fig. S1) has been proposed (Becker et al. 2000; Reuber and Walker 1993). The exo genes responsible for the production, polymerization, and export of succinoglycan are clustered on the $S$. meliloti plasmid pSymB. Each subunit of succinoglycan is an octasaccharide consisting of seven glucose (Glc) residues and one galactose (Gal) residue, decorated with acetyl, succinyl, and pyruval groups (Aman et al. 1982; Reinhold et al. 1994). Polymerization of the octasaccharide subunits results in the formation of long chains that form a high molecular weight (HMW) fraction of EPS. The symbiotically active trimeric form of succinoglycan is generated through the cleavage of HMW chains by the extracellular glycanases ExoK and ExsH (York and Walker 1998).

Investigation of the symbiotic role of EPS is complicated by the production of other polysaccharide molecules by rhizobia that may also play a role in nodulation. These include lipopolysaccharide (LPS), capsular polysaccharide (KPS), and cyclic $\beta$-glucans as well as the production of additional EPS species, including galactoglucan (EPS II) in S. meliloti (Becker et al. 2005; Fraysse et al. 2003; Perret et al. 2000). In addition, it has been thought that rhizobial EPS is only required for infection of indeterminate nodules and that there is no such requirement for determinate nodule formation (Finan et al. 1985; Hotter and Scott 1991; Kim et al. 1989; Ko and Gayda 1990; Pellock et al. 2000). For example, EPS-deficient mutants of Mesorhizobium loti NZP2037 only formed uninfected nodule primordia on the indeterminate host Leucaena leucocephala but formed effective nodules on the determinate host Lotus pedunculatus (Hotter and Scott 1991). However, Staehelin and associates (2006) found that an exoK mutant of the broad-hostrange Rhizobium sp. strain NGR234 that produced only HMW EPS was symbiotically defective on a range of hosts, including some that formed determinate nodules. The mutant formed effective nodules on other hosts.

In this study, we constructed and characterized mutants of M. loti R7A with various defects in the EPS biosynthesis pathway. We report that a subset of EPS mutants displayed severe nodulation deficiencies on the determinate-nodule-forming species L. japonicus and L. corniculatus whereas other mutants formed effective nodules. The infection phenotype of the symbiotically impaired mutants in co-inoculation experiments defined a role for EPS at two developmental stages. Interestingly, the symbiotic phenotypes of the EPS mutants were dependent on the host genotype, environmental conditions, and particular mutant strain, suggesting a complex fine-tuning of the symbiotic interaction.

\section{RESULTS}

\section{Isolation of $M$. loti R7AexoU and R7AexoB mutants.}

$M$. loti R7A was mutagenized with the mini-transposon mTn5-GNm (Reeve et al. 1999) and six nonmucoid colonies that fluoresced more brightly than the wild type on rhizobiumdefined medium with Glc as the sole carbon source (G/RDM) containing $0.02 \%$ Calcofluor were selected, as were two nonmucoid colonies that had wild-type fluorescence. Nodulation assays performed using L. japonicus 'Gifu' as host showed that five of the "bright" mutants were impaired in nodulation whereas the sixth bright mutant and two dark mutants nodulated normally (see below). Sequence analysis showed that the six mTn5-GNm insertions that caused the Calcofluor-bright phenotype were all located within the R7A ortholog of the $M$. loti MAFF303099 gene mlr5261. The insertion in the strain that was not impaired in nodulation was located $83 \mathrm{bp}$ from the $3^{\prime}$ end of the open reading frame and was the most $3^{\prime}$ of the insertions. The Mlr5261 protein shares 59.3\% amino acid identity with the ExoU protein of $S$. meliloti, a glucosyltransferase involved in succinoglycan biosynthesis (Becker et al. 1993; Finan et al. 2001; Glucksmann et al. 1993), and contains a conserved glycosyltransferase domain in the N-terminal end of the amino acid sequence. A mutant with an insertion in the middle of the gene and the mutant with the $3^{\prime}$ insertion (designated R7AexoU and R7AexoU3', respectively) were selected for further work. The insertions in the two mutants that were not altered in their Calcofluor reaction on G/RDM were both within the R7A ortholog of mlr5697, one of four MAFF303099 genes that encode putative UDP-Glc 4-epimerases. The encoded protein was more similar to the chromosomal $S$. meliloti UDPGlc-4-epimerase homolog Smc02252 (65\% identity) than to the $S$. meliloti homologs on the pSymB megaplasmid (ExoB [Smb20942], 44\% identity; and Smb20459, 44\% identity). It also displayed $58.3 \%$ identity to the product of an exoB gene of Azospirillum brasilense that complements $S$. meliloti exoB mutants for UDP-Glc-4-epimerase activity (Michiels et al. 1988). ExoB is involved in the synthesis of UDP-Gal that is the immediate sugar precursor required for the first step of succinoglycan synthesis. One of the two mutants was named $\mathrm{R} 7 \mathrm{AexoB}$ and used for further work.

\section{Construction of further M. loti R7A EPS mutants by directed mutagenesis.}

Bioinformatic analyses indicate that S. meliloti, Rhizobium sp. strain NGR234, and M. loti MAFF303099 share exo genes that, in $S$. meliloti, are required for succinoglycan biosynthesis up to and including the step catalyzed by ExoU, the formation of the hexasaccharide $\left(\mathrm{Gal}-(\mathrm{Glc})_{5}\right)$, but not subsequent steps required for synthesis of the oligosaccharide subunit (Streit et al. 2004). Analysis of M. loti MAFF303099 sequence (Kaneko et al. 2000) indicated the presence of an approximately $30-\mathrm{kb}$ cluster of exo genes, including exoU involved in EPS biosynthesis, polymerization, transport, and post-production processing (Fig. 1). In order to facilitate the isolation of further R7A exo mutants, a cosmid pSK11 was isolated from a genomic DNA cosmid library using a polymerase chain reaction (PCR) screen based on the exoU gene sequence. Sequencing of the 23-kb insert in pSK11 revealed that the organization of the EPS biosynthesis genes in this region of R7A was the same as that of MAFF303099 (Fig. 1), with 98\% nucleotide identity observed between the strains.

Additional $M$. loti EPS-deficient mutant strains disrupted in targeted genes that are predicted to be involved at varying steps of the EPS biosynthetic pathway, based on their location or the known activity of their homologs in S. meliloti, were constructed using markerless deletion (R7A $\Delta$ exoA) or insertional duplication mutagenesis (IDM) (strains R7AexoO, R7AexoK, R7Amlr5265, and R7Amlr5266) strategies (Table 1). The IDM strategy was used for mutant construction after attempts to construct nonpolar markerless deletions in the genes were unsuccessful. In S. meliloti, ExoA is the first glycosyltransferase in the pathway while the ExoO glycosyltransferase catalyses the step prior to that of ExoU. ExoK is an extracellular endo-1,3-1,4- $\beta$ glycanase cleavage enzyme responsible for the cleavage of HMW EPS in the periplasm to form low molecular weight repeating units of EPS. The mlr5265 and mlr5266 genes located downstream of exoK had not been implicated previously in EPS biosynthesis; however, mlr5265 encodes a putative UDP-Glc dehydrogenase responsible for the production of UDP-glucu- 
ronate and $m l r 5266$ also encodes an oxidoreductase, indicating possible roles in EPS biosynthesis.

Phenotypic characterization of EPS mutants.

Following 4 days of growth, all EPS mutants formed small (1- to 2-mm) nonmucoid colonies on G/RDM, except for R7Amlr5266 and R7AexoU3' that formed slightly mucoid colonies compared with the large mucoid colonies formed by R7A (Fig. 2A). Because R7AexoK was nonmucoid, it is likely that the exoK mutation was polar. Strains R7AexoO,
R7Amlr5265, R7AexoU, and R7AexoU3' strongly absorbed Congo red compared with R7A and the other mutants (Fig. 2B). The Calcofluor reactions of the strains differed on tryptone yeast (TY) versus G/RDM medium (Fig. 2C and D). On TY, a gradation from no fluorescence (R7AexoB, R7AexoO, and R7A $\Delta$ exoA) through very weak (R7Amlr5265 and R7AexoK) to moderate (R7AexoU3' and R7Amlr5266) or strong fluorescence (R7A and R7AexoU) was observed. In contrast, on G/RDM, only R7AexoU, R7AexoU3', R7Amlr5265, and R7Amlr5266 showed significant fluorescence. R7A fluoresced

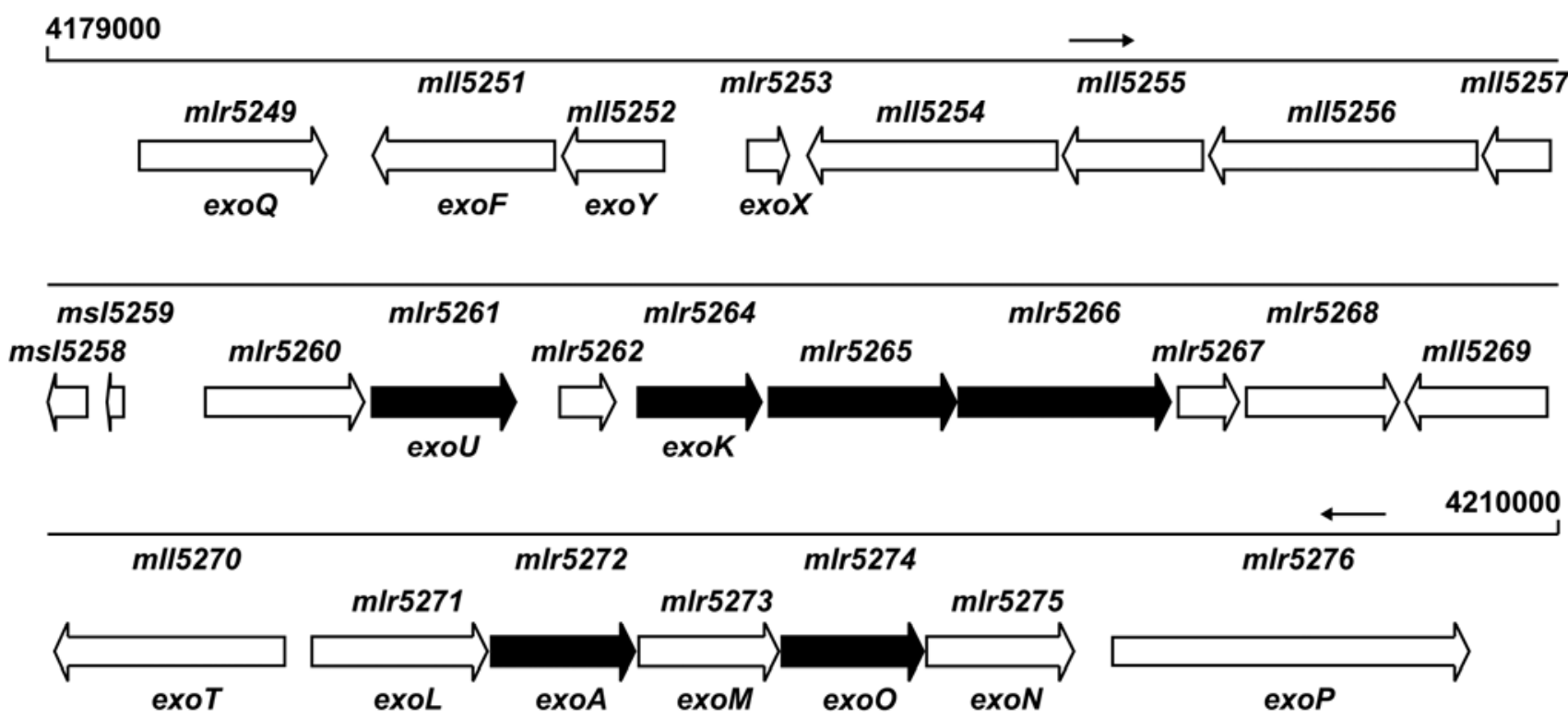

Fig. 1. Cluster of exo genes identified in MAFF303099 was found to be present in identical arrangement in R7A with 98\% nucleotide identity. Ends of the R7A cosmid pSK11 are indicated by arrows and the MAFF303099 genome co-ordinates of the region are displayed. Black genes indicate those in which mutants were constructed in this study.

Table 1. Bacterial strains and plasmids

\begin{tabular}{|c|c|c|}
\hline Strain & Relevant characteristics $^{\mathbf{a}}$ & Reference, source \\
\hline \multicolumn{3}{|c|}{ Mesorhizobium spp. } \\
\hline R7A & Parent strain, field reisolate of ICMP3153 (NZP2238) originally isolated in Ireland & Sullivan et al. 2002 \\
\hline R7AexoB & $\mathrm{R} 7 \mathrm{~A}$ exoB::mTn5, $\mathrm{Nm}^{\mathrm{r}}$ & This study \\
\hline R7AexoU & $\mathrm{R} 7 \mathrm{~A}$ exoU::mTn5, $\mathrm{Nm}^{\mathrm{r}}$ & This study \\
\hline R7AexoU3' & R7A exoU::mTn5, insertion 83 bp from 3' end of the gene, $\mathrm{Nm}^{\mathrm{r}}$ & This study \\
\hline R7AexoO & $\mathrm{R} 7 \mathrm{~A}$ exoO $:: \mathrm{pFUS} 2, \mathrm{Gm}^{\mathrm{r}}$ & This study \\
\hline R7AexoK & R7A exoK::pFUS2, Gm ${ }^{\mathrm{r}}$ & This study \\
\hline R7A5265 & R7A mlr5265::pFUS2, Gm ${ }^{\mathrm{r}}$ & This study \\
\hline R7A5266 & R7A mlr5266::pFUS2, $\mathrm{Gm}^{\mathrm{r}}$ & This study \\
\hline R7A $\triangle$ exoA & R7A exoA in-frame markerless deletion & This study \\
\hline $\mathrm{R} 7 \mathrm{~A} \Delta \mathrm{ndvB}$ & R7A $n d v B$ in-frame markerless deletion & This study \\
\hline R7AexoBexoU & R7AexoB containing an exoU::pFUS2 insertion, $\mathrm{Nm}^{\mathrm{r}}, \mathrm{Gm}^{\mathrm{r}}$ & This study \\
\hline R7ALZ & R7A containing pXLGD $4, \mathrm{Tc}^{\mathrm{r}}$ & This study \\
\hline R7AexoULZ & R7AexoU containing pXLGD $4, \mathrm{Tc}^{\mathrm{r}}$ & This study \\
\hline \multicolumn{3}{|l|}{ Escherichia coli } \\
\hline 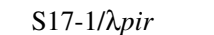 & RP4:2 tra region, pir, host for pir-dependent plasmids & Herrero et al. 1990 \\
\hline \multicolumn{3}{|l|}{ Plasmids } \\
\hline pCRS487 & pUT::mTn5-GNm, $\mathrm{Ap}^{\mathrm{r}}, \mathrm{Km}^{\mathrm{r}}$ & Reeve et al. 1999 \\
\hline pFAJ1700 & Stable RK2-derived cloning vector, $\mathrm{Ap}^{\mathrm{r}}, \mathrm{Tc}^{\mathrm{r}}$ & Dombrecht et al. 2001 \\
\hline pFAJ1708 & $\begin{array}{l}\text { Stable RK2-derived cloning vector containing the promoter of the } n p t I I \text { gene in the multiple cloning } \\
\text { site, } \mathrm{Ap}^{\mathrm{r}}, \mathrm{Tc}^{\mathrm{r}}\end{array}$ & Dombrecht et al. 2001 \\
\hline pFUS2 & Suicide vector, oriV ColE1 , oriT, $\mathrm{Gm}^{\mathrm{r}}$ & Antoine et al. 2000 \\
\hline pJQ200SK & pACYC derivative, oriV ${ }^{\mathrm{p} 15 \mathrm{~A}}, s a c B \mathrm{Gm}^{\mathrm{r}}$ & Quandt and Hynes, 1993 \\
\hline pXLGD4 & pGD499 prime, IncP, carrying a hemA::lacZ fusion & Leong et al. 1985 \\
\hline pSK11 & pIJ3200 containing $22.8 \mathrm{~kb}$ of R7A genomic DNA encoding large part of exo gene cluster, $\mathrm{Tc}^{\mathrm{r}}$ & This study \\
\hline pSKKSG1 & pFAJ1700 containing an exoK single-gene complementation product with 154 -bp promoter region, $\mathrm{Tc}^{\mathrm{r}}$ & This study \\
\hline pSKKSG2 & pFAJ1700 containing an exoK single-gene complementation product with 387 -bp promoter region, $\mathrm{Tc}^{\mathrm{r}}$ & This study \\
\hline pSKLASG & pFAJ1700 containing an exoL-exoA complementation product, $\mathrm{Tc}^{\mathrm{r}}$ & This study \\
\hline pSKUSG & pFAJ1700 containing an exoU single-gene complementation product, $\mathrm{Tc}^{\mathrm{r}}$ & This study \\
\hline pSKDSRED & pFAJ1708 containing dsred.t4, $\mathrm{Tc}^{\mathrm{r}}$ & This study \\
\hline pSKGFP & pFAJ1700 containing $g f p$ expressed from the $n p t I I$ promoter, $\mathrm{Tc}^{\mathrm{r}}$ & This study \\
\hline
\end{tabular}

${ }^{\mathrm{a}} \mathrm{Nm}^{\mathrm{r}}, \mathrm{Gm}^{\mathrm{r}}, \mathrm{Tc}^{\mathrm{r}}, \mathrm{Ap}^{\mathrm{r}}$, and $\mathrm{Km}^{\mathrm{r}}=$ resistant to neomycin, gentamicin, tetracycline, ampicillin, and kanamycin, respectively. 
strongly on TY but very weakly on G/RDM, suggesting that the copious EPS production of R7A on G/RDM blocked access of Calcofluor to its binding substrate. A fluorescent halo was observed around R7AexoU and R7AexoU3' growth on G/RDM plates containing Calcofluor (Fig. 2D). In summary, strains R7A $\triangle$ exoA and R7AexoB behaved identically on the three media whereas the other mutants could be uniquely distinguished.

Introduction of pSK11 restored mucoid growth to strains R7AexoU, R7AexoO, R7AexoK, R7Amlr5265, R7Amlr5266, and R7A $\Delta$ exoA. The R7AexoU and R7A $\Delta$ exoA mutants were also complemented by pSKUSG and pSKLASG that express exoU and exoLA, respectively, from their native promoter regions. In contrast, R7AexoK was not complemented by pSKKSG1 or pSKKSG2 that contain exoK together with preceding noncoding regions of 154 and $387 \mathrm{bp}$, respectively, confirming that the mutation was polar.

\section{Characterization of EPS from R7A and mutant strains.}

EPS preparations extracted from culture supernatants of R7A, several of the EPS mutant strains, and an R7A mutant deficient in cyclic $\beta$-glucans (strain R7A $\Delta$ ndvB) were partially characterized. Size fractionation of the extracts by Sephacryl S-400 gel permeation chromatography showed that R7A (Fig. 3A), R7A $\Delta$ ndvB, and R7AexoU3' (Supplementary Fig. S2A) produced both HMW EPS and as-yet-uncharacterized lower molecular weight (LMW) polysaccharide fractions. Strains R7AexoB (Fig. 3A), R7AexoU (Fig. 3A), R7A $\Delta$ exoA, R7AexoO, R7AexoK, and R7Amlr5265 (data not shown) produced only LMW polysaccharide fractions.
To determine the basic composition of EPS and LMW polysaccharides produced by R7A, R7A $\Delta$ ndvB, R7AexoU, R7AexoU3', and R7AexoB, samples were converted to trimethylsilyl methyl esters (TMS) methyl glycosides and analyzed by gas chromatography mass spectrometry (GC-MS) (Fig. 3B). R7A EPS consisted largely of Glc and Gal with lesser amounts of glucuronic acid (GlcA). Both R7A $\Delta$ ndvB and R7AexoU3' mutants produced EPS similar to that of R7A. In comparison, only Glc was detected in the LMW polysaccharide extracts of the R7AexoB and R7AexoU mutants. Glycosyl linkage analysis indicated that approximately $25 \%$ of the Glc from LMW polysaccharide fractions from R7A and from the EPS mutant strains was 2-Glc, which was likely derived from cyclic $\beta$-glucan because it was absent from R7A $\Delta$ ndvB extracts (our unpublished data). This implies that the LMW fractions comprised both cyclic $\beta$-glucan and other polysaccharides.

A penturonic acid residue was also detected in R7A EPS. This residue was observed after the EPS was carboxyl-methyl esterified, reduced, and subsequently hydrolyzed, reduced again, and converted to alditol acetates (AA). GC-MS analysis of the AA using electron impact and chemical ionization fragmentation indicated the presence of riburonic acid (RibA) (Supplementary Fig. S3). These results, together with proton NMR analysis, determined that R7A EPS is composed of Glc, Gal, GlcA, and RibA. The EPS was O-acetylated but lacked other components such as pyruvate and succinate that are found in S. meliloti succinoglycan (A. Muszyński and R. W. Carlson, unpublished data).

Because $e x o B$ is involved in the synthesis of UDP-Gal, it was possible that strain R7AexoB was affected in other polysaccharides that contain Gal. Composition analysis indicated
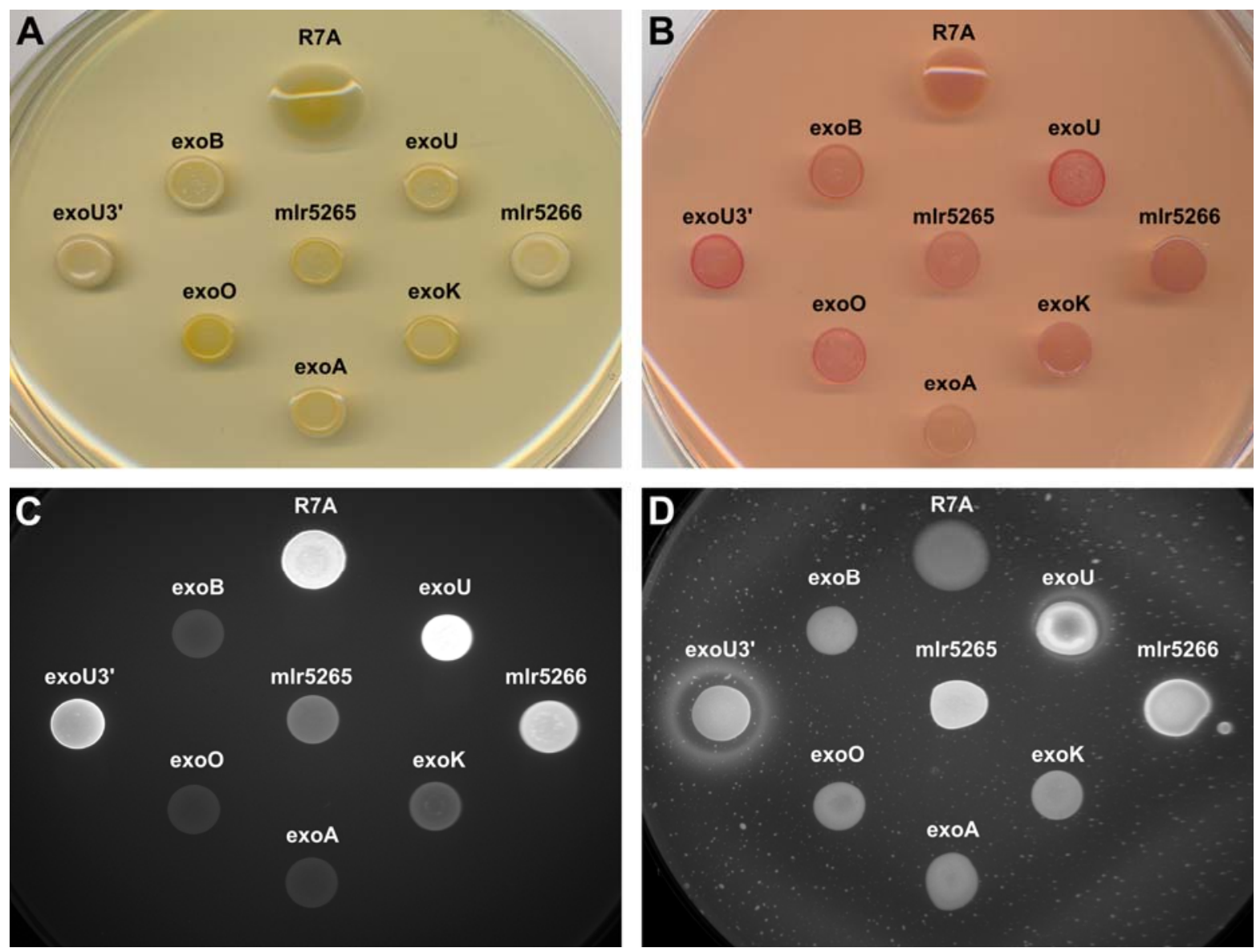

Fig. 2. Tryptone yeast (TY) broth cultures were grown for $48 \mathrm{~h}$ and then spotted (10 $\mu \mathrm{l})$ onto the various media. A, Colony growth of the indicated strains on rhizobium-defined medium with glucose as the sole carbon source (G/RDM) after $96 \mathrm{~h}$. B, Colony growth on yeast mannitol broth containing $0.005 \%$ Congo red after $48 \mathrm{~h}$. $\mathbf{C}$ and $\mathbf{D}$, Colony fluorescence observed under UV light after $48 \mathrm{~h}$ of growth on $\mathbf{C}$, TY and D, G/RDM containing $0.02 \%$ Calcofluor. 
that R7AexoB had an altered LPS that lacked Gal compared with LPS from R7A and R7AexoU (Supplementary Fig. S4).

\section{Symbiotic properties of the EPS mutants.}

The ability of the EPS mutant strains to form nitrogen-fixing nodules on L. corniculatus (Fig. 4A) and L. japonicus 'Gifu' (Fig. 4B) differed depending on the mutant and host. Strains R7AexoB and R7AexoU3' formed effective nodules on both hosts at a similar rate to strain R7A. L. corniculatus plants inoculated with R7A $\triangle$ exoA exhibited a slight delay in the formation
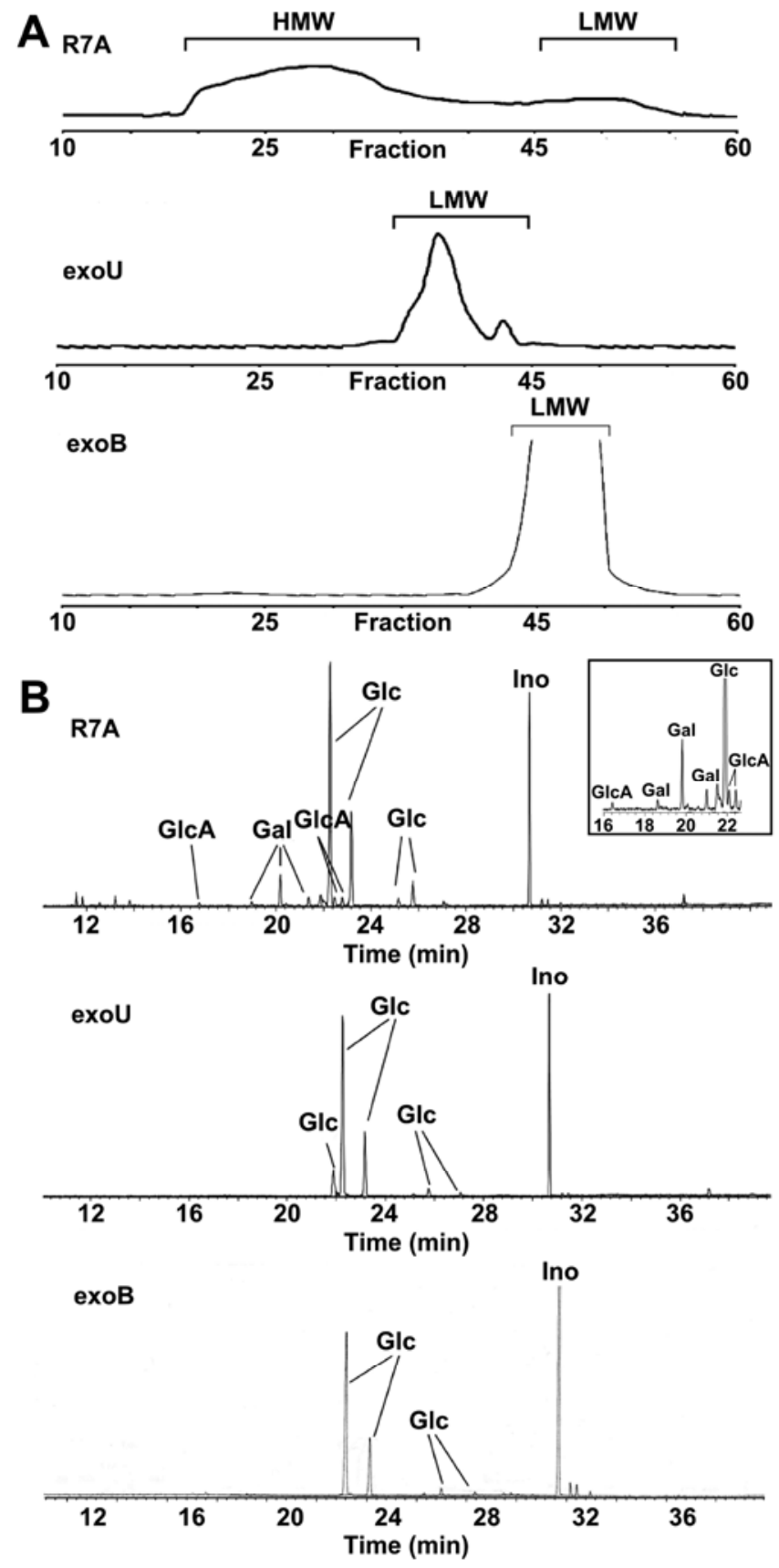

Fig. 3. A, Crude exopolysaccharide (EPS) extracts size-fractionated by Sephacryl S-400 size exclusion chromatography. High molecular weight (HMW) and lower molecular weight (LMW) polysaccharide fractions are indicated. B, R7A, R7AexoU, and R7AexoB polysaccharide samples were converted to trimethylsilyl-methyl glycosides and the glycosyl composition was determined by gas chromatography mass spectrometry. Glc, glucose; Gal, galactose; GlcA, glucuronic acid; and Ino, myo-inositol (added as an internal standard). The inset represents a closer view of the retention time at which GlcA and Gal were detected. of effective nodules, initially forming white nodule primordia that developed into effective nodules within a few days. On $L$. japonicus 'Gifu', R7A $\Delta$ exoA induced mainly white nodule primordia, only a few of which developed into effective nodules after a delay. The other exo mutants were symbiotically impaired on both hosts. Strains R7AexoU, R7AexoO, and R7Amlr5265 formed white nodule primordia and, only following prolonged incubation, the occasional effective nodule (Fig. 4). R7AexoK and R7Amlr5266 had an intermediate phenotype between the R7AexoB and R7AexoU phenotypes. Shoot growth of plants inoculated with the exo mutants reflected the ability of the strain to induce effective nodules (Supplementary Fig. S5). Bacteria recovered from late-appearing nodules formed by R7AexoU maintained the exoU free-living and symbiotic phenotypes, indicating that the nodules were "escape" nodules and not formed by suppressor mutants or revertants.

The possibility existed that R7AexoB produced small amounts of functional EPS that accounted for its ability to nodulate. To investigate this, an exoB exoU double mutant was constructed by introducing a pFUS2::exoU construct into R7AexoB. The resultant strain R7AexoBexoU showed the exoB phenotype, forming effective nodules on both hosts.
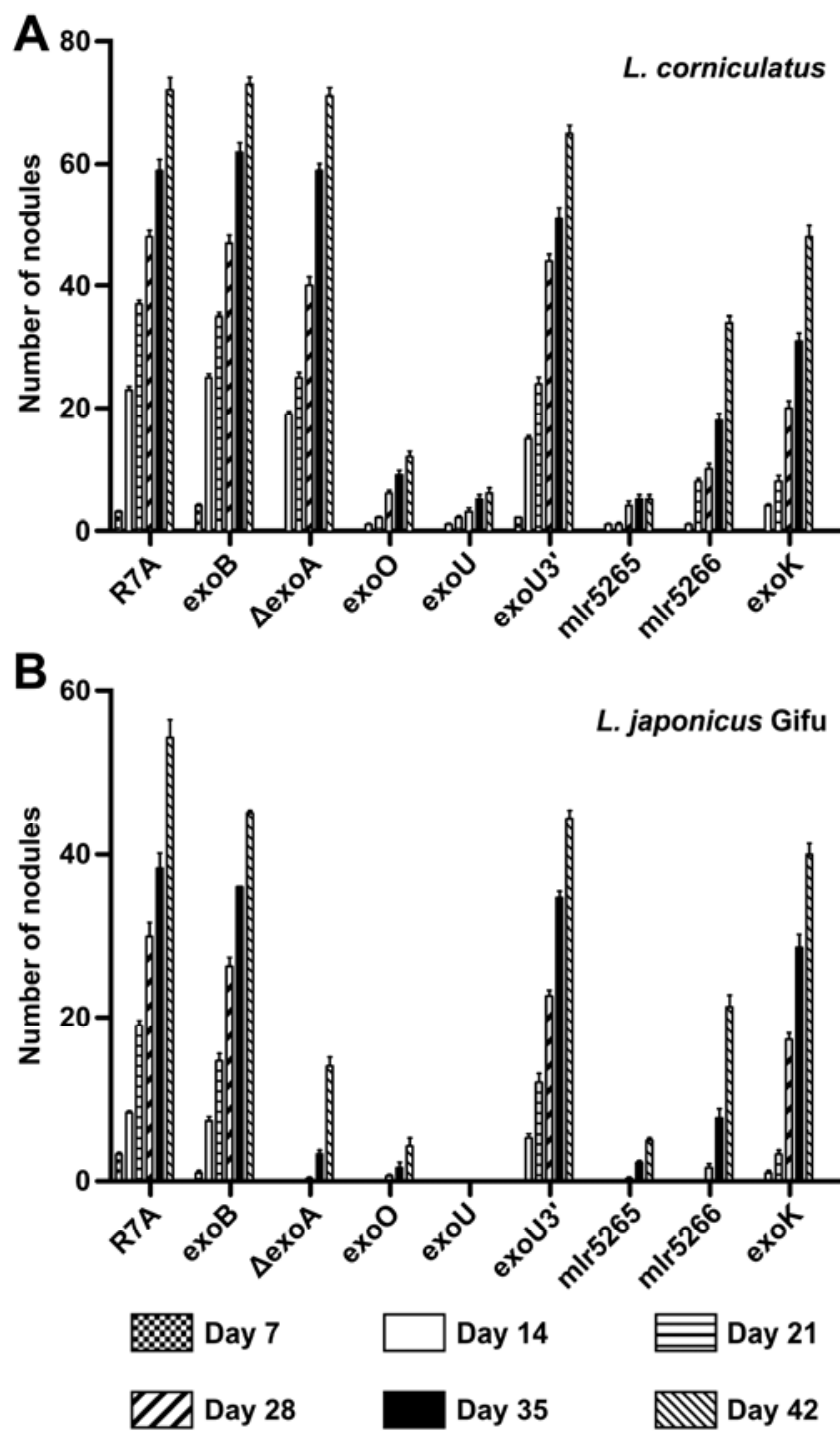

Fig. 4. Total number of nitrogen-fixing nodules formed on 10 plants of $\mathbf{A}$, Lotus corniculatus and B, L. japonicus 'Gifu' inoculated with the indicated strains. Results represent three independent nodulation assays, with error bars indicating the standard error of the mean. 


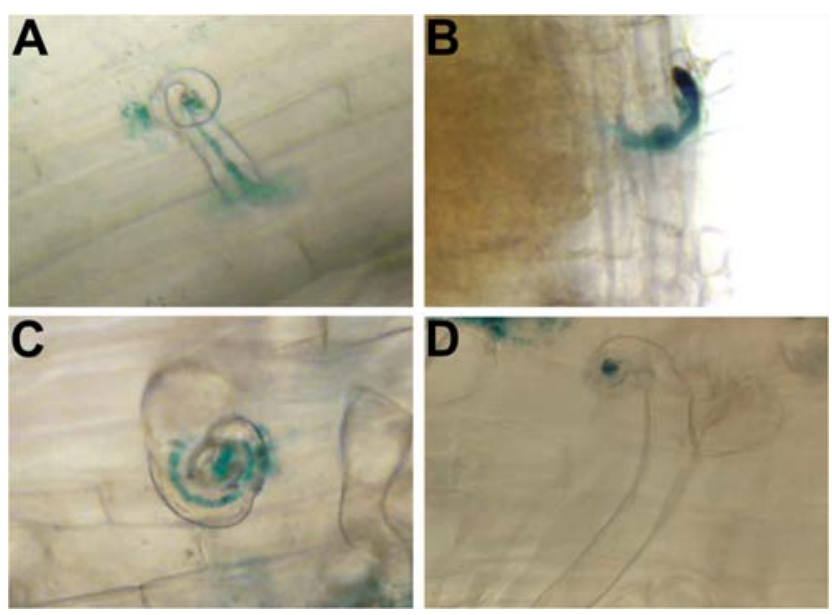

Fig. 5. R7A formed extended infection threads (IT) on both A, Lotus corniculatus and $\mathbf{C}$, L. japonicus 'Gifu'. R7AexoU was impaired in IT formation, forming only $\mathbf{B}$, the occasional swollen IT on $L$. corniculatus and D, infection focal points on L. japonicus 'Gifu' .

A
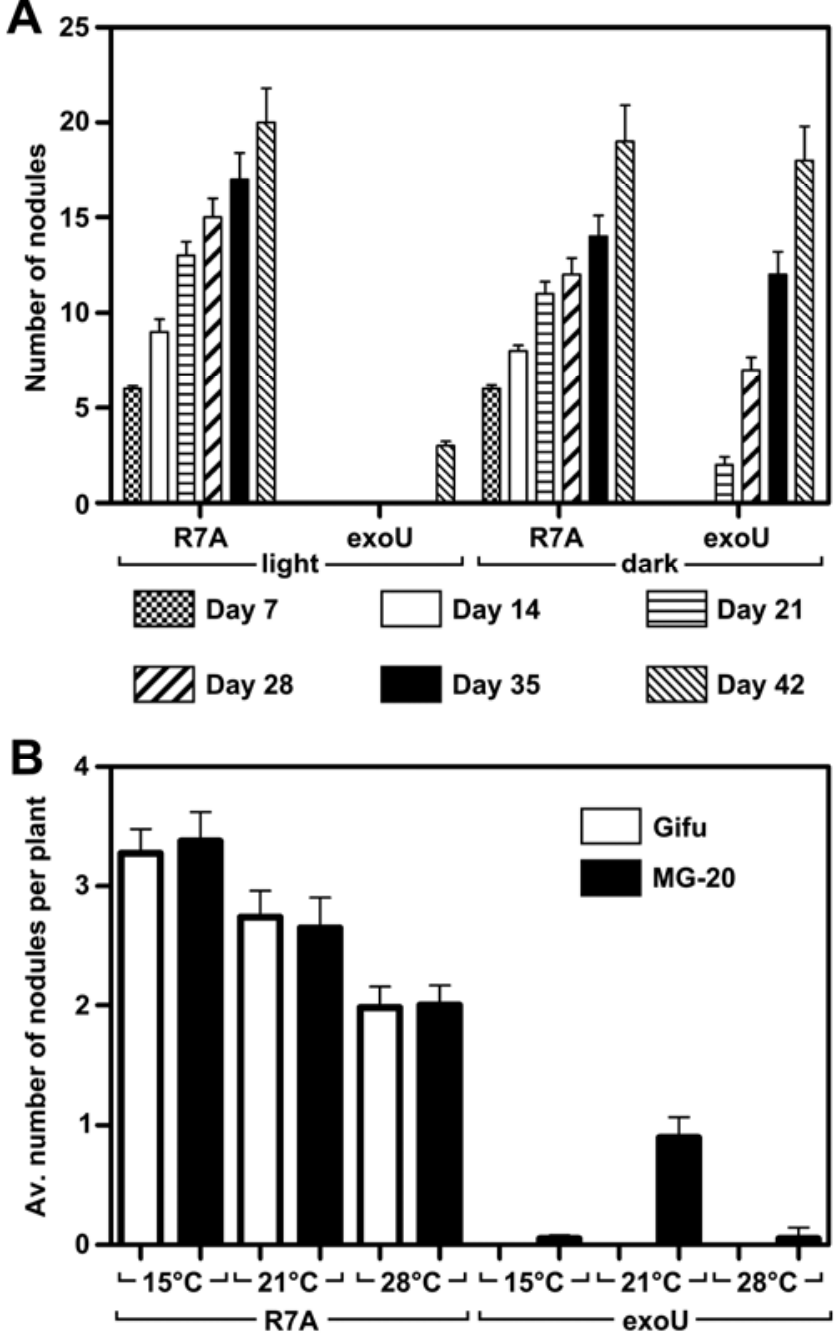

Fig. 6. A, Total number of nitrogen-fixing nodules formed on 10 plants of Lotus japonicus MG-20 inoculated with R7A or R7AexoU and grown with roots exposed to the light or kept in the dark. Results represent three independent nodulation assays with the standard error of the mean indicated. B, Average number of nitrogen-fixing nodules formed on 30 to 40 L. japonicus 'Gifu' or L. japonicus MG-20 inoculated with R7A or R7AexoU and grown with roots in the dark at the indicated temperatures. Error bars indicate standard error of the mean.
The symbiotic impairment of R7AexoU is at the stage of IT initiation.

Strain R7AexoU was used for further characterization of the symbiotically defective class of EPS mutants. Examination of R7A- and R7AexoU-inoculated L. japonicus 'Gifu' roots 2 days post inoculation (dpi) showed that R7AexoU was unaffected in its ability to induce early host symbiotic responses, including root hair swelling and curling. Strains R7A and R7AexoU containing plasmid pXLGD4 that constitutively expresses the lacZ reporter gene were used to assay IT formation on L. corniculatus and L. japonicus 'Gifu' roots at 10 to 14 dpi. An average of 9 IT per root was observed on R7A/pXLGD4-inoculated roots (Fig. 5A and C). In contrast, R7AexoU/pXLGD4-inoculated plants displayed microcolonies within curled root hair tips on both hosts (Fig. 5D) and, in rare instances, a swollen truncated IT on L. corniculatus (Fig. 5B), but no fully extended IT.

R7AexoU displays host ecotype- and environment-specific symbiotic phenotypes.

The symbiotic proficiency of R7AexoU was examined on 65 L. japonicus ecotypes (Supplementary Fig. S6). The majority (40 of 65) formed white primordia with only the occasional pink nodule developing. At least one pink nodule as well as primordia developed on 25 to $50 \%$ of inoculated plants from 17 genotypes and on 50 to $75 \%$ of plants from the remaining eight genotypes, including MG-20. No correlation between geographic origin of the ecotypes and nodule formation by R7AexoU was observed.

Nodulation of L. japonicus 'Gifu' and L. japonicus MG-20 by R7AexoU was further investigated under various environmental conditions. Seedlings were grown with roots either in the dark or exposed to light and at incubation temperatures of 15,21 , and $28^{\circ} \mathrm{C}$. R7A formed nodules on both hosts at comparable rates under all environmental conditions. L. japonicus 'Gifu' inoculated with R7AexoU failed to form nodules under any of the conditions. On MG-20, R7AexoU formed nodules on $57 \%$ of plants when roots were kept in the dark at $21^{\circ} \mathrm{C}$; however, only very few late-arising nodules developed on roots exposed to light (Fig. 6A). Nodulation of dark-grown MG-20 roots by R7AexoU was temperature dependent, because only a few nodules formed on plants grown at 15 or $28^{\circ} \mathrm{C}$ (Fig. 6B).

\section{Nod factor and EPS mutant strains}

functionally complement each other.

The role of R7A EPS during symbiosis was further investigated through plant co-inoculation assays involving Nod-factordeficient R7A $\Delta$ nodA (Rodpothong et al. 2009) and EPS-deficient R7AexoU mutant strains. Plasmids constitutively expressing green fluorescent protein (GFP) or DsRed were introduced into the strains to allow their differentiation, and inoculated $L$. japonicus 'Gifu' seedlings were examined 7 to 21 dpi by epifluorescent and confocal microscopy. As a sole inoculum, R7A $\Delta$ nodA failed to induce any plant responses. As expected, seedlings inoculated with R7AexoU displayed root hair deformation with associated microcolonies but no IT, and the establishment of nodule primordia. No nodules had developed on any seedling inoculated with either the Nod factor- or EPS-deficient strain by $21 \mathrm{dpi}$. In contrast, seedlings inoculated with a 1:1 mix of the two strains formed nodules with only a slight delay compared with R7A-inoculated plants.

The dynamics of IT development and nodule occupancy on co-inoculated L. japonicus 'Gifu' were examined. Plants were inoculated with 1:1 mixtures of R7A $\Delta$ nodA and R7AexoU using both possible combinations of reporter plasmids in the strains to rule out any reporter gene bias. Over 100 IT and 10 nodules were examined on plants inoculated with each mixture 
to determine the occupying strains (Table 2). On control plants inoculated with a 1:1 mix of R7A containing the different reporter constructs, approximately $50 \%$ of the IT were formed by each reporter strain, with only one mixed IT observed. Of the nodules that formed on control plants, $90 \%$ harbored only one of the reporter strains. On R7A $\Delta$ nodA/R7AexoU-inoculated plants, approximately seven extended IT were readily observed per plant root. Of these, $80 \%$ appeared to contain R7AexoU alone, $10 \%$ R7A $\Delta$ nodA alone, and $10 \%$ were mixed (Fig. 7). Dual nodule occupancy was observed in $80 \%$ of the nodules that formed on R7A $\Delta$ nodA/R7AexoU-inoculated plants, with individual plant cells containing either one or both strains (Fig. 7E and F).

\section{DISCUSSION}

In this work, we show that the symbiotic phenotype of EPS mutants of $M$. loti R7A is influenced by the particular mutant, host plant ecotype, and environmental conditions. The exoB mutants, predicted to be affected in the synthesis of UDP-Gal required for the first step of EPS biosynthesis, formed nitrogen-fixing nodules on $L$. corniculatus and L. japonicus 'Gifu'. Strain R7A $\Delta$ exoA, predicted to be affected in the addition of the first glucosyl residue, was symbiotically proficient follow- ing a slight delay on L. corniculatus but induced mostly uninfected nodule primordia on L. japonicus 'Gifu' and, after a delay, a few effective nodules. In contrast, strains disrupted in the middle to late steps of EPS synthesis (R7AexoO, R7AexoU, R7AexoK, R7Amlr5265, and R7Amlr5266) were equally impaired on both hosts, with the severity of the symbiotic defect dependent on the particular mutant. The exoU, exoO, and mlr5265 mutants exhibited the most severe symbiotic phenotype and induced mostly the formation of small, uninfected nodule primordia. This phenotype is similar to that described for EPS mutants of $S$. meliloti and R. leguminosarum that are impaired in their symbiosis with indeterminate-nodule-forming hosts. These $M$. loti exo mutants were disrupted at the stage of IT development.

The possibility that the $e x o B$ mutant was able to form effective nodules due to the production of small quantities of fulllength EPS was ruled out by the finding that an R7AexoBexoU double mutant showed the exoB mutant phenotype. Hence, the phenotype of this strain indicates that rhizobial EPS produced by the pathway characterized in this study is not required for an effective symbiosis on Lotus spp. The symbiotic ability of R7AexoB may be due to either complementary signaling by an alternative polysaccharide in the absence of wild-type EPS production or the absence of surface molecules that the plant

Table 2. Infection thread (IT) and nodule occupancy of Lotus japonicus 'Gifu' co-inoculated with R7AexoU and R7A $\Delta$ nodA ${ }^{\mathrm{a}}$

\begin{tabular}{|c|c|c|c|c|c|c|}
\hline \multirow[b]{2}{*}{ Mixed inocula (1:1) } & \multicolumn{3}{|c|}{ Strains within IT } & \multicolumn{3}{|c|}{ Strains within nodule } \\
\hline & $\mathbf{G}$ & $\mathbf{R}$ & $\mathbf{G}$ and $\mathbf{R}$ & G & $\mathbf{R}$ & $G$ and $R$ \\
\hline R7A/pSKGFP and R7A/pSKDSRED & 94 & 100 & 1 & 4 & 5 & 1 \\
\hline $\mathrm{R} 7 \mathrm{~A} \Delta \operatorname{nodA} / \mathrm{pSKGFP}$ and R7AexoU/pSKDSRED & 15 & 75 & 12 & 4 & 0 & 8 \\
\hline R7AexoU/pSKGFP and R7A $\Delta$ nodA/pSKDSRED & 92 & 13 & 8 & 0 & 1 & 11 \\
\hline
\end{tabular}

${ }^{a}$ Each IT and nodule formed on co-inoculated plants was determined by epifluorescent microscopy to harbor either only green fluorescent protein (GFP)fluorescent bacteria (G), only DsRed-fluorescent bacteria (R), or a mix of both GFP- and DsRed-fluorescent bacteria (G and R).
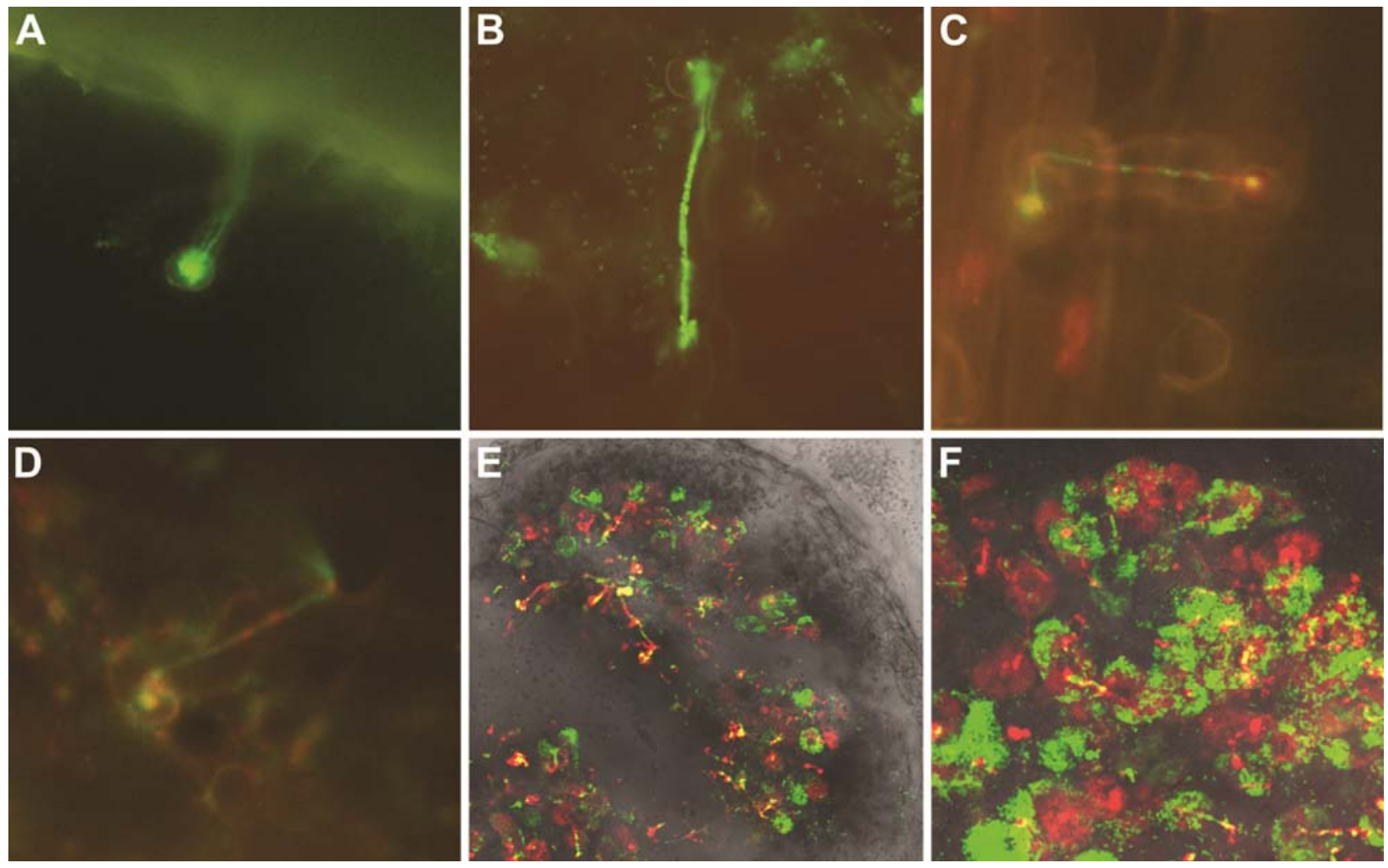

Fig. 7. Extended infection threads (IT) formed on Lotus japonicus 'Gifu' co-inoculated with R7AexoU and R7A $\Delta$ nodA that appeared to contain A, R7A $\Delta$ nodA or B, R7AexoU alone. C and D, Examples of mixed IT formed on co-inoculated plants. Images represent a combined overlay of identical fields of view observed with green fluorescent protein and DsRed filters. $\mathbf{E}$ and $\mathbf{F}$, Confocal microscopy of mixed nodules formed on co-inoculated plants. 
normally perceives to activate a defense response. $S$. meliloti and $R$. leguminosarum exoB mutants are impaired in nodulation and are defective not only in EPS production but also in other Gal-containing polysaccharides, including LPS (Canter Cremers et al. 1990; Sanchez-Andujar et al. 1997). M. loti NZP2213 LPS has been structurally defined and contains Gal (Russa et al. 1995). Composition analysis indicated that Gal was present in R7A LPS but absent in R7AexoB LPS preparations. Thus, in addition to the absence of EPS, the production of an altered LPS may also contribute to the biological effect of the exoB mutation. It is known, for example, that $M$. loti LPS induces nitric oxide production in Lotus roots, which is involved in plant defense response signaling (Murakami et al. 2011; Nagata et al. 2008). Elucidation of possible roles of LPS in the plant response to $\mathrm{R} 7 \mathrm{AexoB}$ requires further investigation. The alternative explanation that R7AexoB avoids eliciting a defense response due to its complete lack of EPS production is consistent with the finding that R7A $\Delta$ exoA was only slightly impaired on L. corniculatus and moderately impaired on L. japonicus, compared with the more severe phenotypes of other EPS mutants.

Apart from R7AexoB and R7A $\Delta$ exoA, the EPS mutants could be distinguished from each other by their reactions on media containing Congo red or Calcofluor. The differing reactions are likely to reflect the cell surface characteristics of the particular mutant, such as the amount and structure of truncated EPS produced. Calcofluor-containing media have long been used to differentiate rhizobial EPS mutants (Glucksmann et al. 1993; Hotter and Scott 1991; Laus et al. 2004; Leigh et al. 1985; Long et al. 1988), although the cause of the fluorescence varies with the organism under study. Succinoglycanproducing strains of $S$. meliloti fluoresce under UV light when grown on Calcofluor media while EPS-deficient strains do not (Gonzalez et al. 1996) whereas, with other rhizobia (e.g., Rhizobium sp. strain NGR234) (Zhan et al. 1990), EPS production results in nonfluorescent growth while EPS mutant strains fluoresce. The observation of a fluorescent halo around R7AexoU and R7AexoU3' colonies grown on Calcofluor-containing G/RDM suggests that Calcofluor was binding to an LMW molecules produced by these strains that diffused into the medium. These molecules likely represent truncated forms of EPS. The production of truncated EPS by an S. meliloti exoO mutant has previously been reported (Glucksmann et al. 1993). The exoO mutant is disrupted in succinoglycan biosynthesis at the stage of the addition of the fourth glucosyl residue that forms the first residue of the branch chain in the mature EPS, the step immediately prior to that involving ExoU. Therefore, the differing colony phenotypes of the various EPS mutants on media containing Calcofluor or Congo red may reflect the absence of EPS (e.g., R7AexoB and R7A $\Delta$ exoA) or the production of differing truncated forms of EPS that reflect the EPS biosynthetic step at which the mutant was disrupted. All mutations examined in this work other than $e x o B$ and exo $A$ are predicted, on the basis of the succinoglycan structure, to affect the addition of residues to the branch chain and, hence, the mutants may export truncated EPS. It is possible that this truncated EPS is perceived by the plant, leading to the induction of a defense response that prevents IT development.

R7A produced HMW and LMW fractions of EPS that consisted of Glc, Gal, GlcA, and RibA (this work; A. Muszyński and R. W. Carlson, unpublished data), a composition similar to that previously reported for $S$. meliloti IFO13336 and $M$. huakuii My6 (Amemura et al. 1981; Hisamatsu et al. 1997). Other than strain R7AexoU3', the EPS mutants examined in this study produced only an LMW polysaccharide fraction, in which only Glc was detected. Strain R7AexoU3' grown on G/RDM containing Calcofluor initially formed small, nonmu- coid colonies surrounded by halo that were indistinguishable from those formed by R7AexoU; however, following prolonged incubation, the colonies became slightly mucoid, indicating that the strain was producing some HMW EPS that composition analysis confirmed was similar to that from strain R7A. Strain R7AexoU3' formed nodules at rates comparable with R7A despite its colony morphology, indicating production of much lower quantities of EPS compared with R7A. Because R7AexoU3' still produced truncated EPS, this suggests that small quantities of full-length EPS are sufficient to allow nodulation to proceed, supporting a signaling rather than protective or structural role for EPS in symbiosis. This signaling may lead to the suppression of a defense response that would otherwise be induced by the mutant strain.

Co-inoculation of plants with the Nod factor-deficient strain R7A $\Delta$ nodA and the EPS-deficient strain R7AexoU revealed that full-length EPS provided in trans was sufficient to allow successful nodulation, again supporting a signaling role for fulllength EPS in suppressing the symbiotic defect of R7AexoU. Most of the nodules formed in the co-inoculation assays harbored both strains whereas the majority of IT observed contained solely R7AexoU. This suggests that, although mixed IT formed only a small proportion of the total IT observed, they were able to develop fully and allow entry of both strains into the nodule. In the case of the IT harboring R7AexoU alone, EPS provided in trans by the Nod factor mutant allowed R7AexoU to initiate IT development and extension; however, because few nodules were found to contain R7AexoU alone, it would seem that release from the IT into the nodule primordia cells was inhibited. This suggests that R7A EPS was required both for IT initiation by R7AexoU and release of the strain from IT. The requirement for EPS at the stage of IT release may provide a further checkpoint for the plant to prevent nonsymbionts infecting the plant through "hitchhiking" in the IT.

The symbiotic proficiency of R7AexoU was host dependent, as demonstrated by the examination of nodule formation on 65 L. japonicus ecotypes following inoculation with the strain. On the majority of ecotypes, R7AexoU induced small, uninfected bumps, as described above; however, on other ecotypes, the strain induced several nitrogen-fixing nodules. As well as host specificity, environmental conditions, including root lighting conditions and temperature variations, affected the nodulation ability of R7AexoU on L. japonicus MG-20. Under conditions where the plant was subjected to these environmental stresses, R7AexoU was much less successful in forming nodules compared with R7A. One explanation for the observed environmental effects is that R7AexoU is unable to overcome cumulative plant responses to these stresses and rhizobial infection as efficiently as R7A. Examining the differences in plant responses to inoculation by R7AexoU between host and environmental conditions that were permissive or nonpermissive to nodulation by R7AexoU should yield insight into the role of EPS in the symbiotic process.

This study demonstrated a symbiotic role for R7A EPS in determinate nodulation, although host, environmental conditions, and the particular EPS mutant strain all have an effect on the outcome of the interaction. We propose that full-length EPS produced by wild-type $M$. loti R7A acts as a signal to compatible hosts to modulate plant defense responses and allow full IT development and bacterial release. R7A EPS mutant strains that produce no EPS via the characterized pathway, due to mutations that affect the beginning of EPS biosynthesis, avoid or suppress the plant surveillance system and are able to form nodules. However, strains that are disrupted midway through EPS biosynthesis are symbiotically impaired at the stage of IT development due to the truncated forms of EPS produced by these strains, inducing plant defense responses. 


\section{MATERIALS AND METHODS}

Strains, plasmids, and media.

Bacterial strains and plasmids used in this study are listed in Table 1. M. loti strains were cultured at $28^{\circ} \mathrm{C}$ in $\mathrm{TY}$ broth (Beringer 1974) or RDM (Ronson et al. 1987) broths and agar plates, usually supplemented with $0.4 \%$ Glc as the sole carbon source (G/RDM). RDM with $5 \%$ sucrose as the sole carbon source was utilized in the construction of strain R7A $\Delta$ exoA. Calcofluor media were TY or G/RDM with the addition of $0.02 \%$ (wt/vol) Fluorescent brightener-28 (F3543; Sigma, St. Louis). Congo red medium was yeast mannitol agar (Vincent 1970) containing $0.005 \%$ (wt/vol) Congo red dye (C6277; Sigma). For $M$. loti, antibiotics were added to media as required at the following concentrations: neomycin $(200 \mu \mathrm{g} / \mathrm{ml})$, gentamicin $(50 \mu \mathrm{g} / \mathrm{ml})$, tetracycline $(2.5 \mu \mathrm{g} / \mathrm{ml})$, and rifampicin $(10 \mu \mathrm{g} / \mathrm{ml})$.

\section{Isolation of R7A EPS mutants.}

Strains R7AexoB, R7AexoU, and R7AexoU3' were isolated by random mutagenesis of R7A with the transposon mTn5NmG (Reeve et al. 1999). pCRS487, which carries mTn5-Nm, was introduced into R7A through filter-matings using $1 \mathrm{ml}$ each of stationary phase TY broth culture of appropriate strains filtered through $0.45-\mu \mathrm{m}$ filters (Type HA, $47 \mathrm{~mm}$; Millipore Corporation, Bedford, MA, U.S.A.) using a vacuum filter apparatus. Filters were transferred to a TY agar plate and incubated at $28^{\circ} \mathrm{C}$ overnight. Mating growth was re-suspended in $0.9 \%$ saline and dilutions were plated on G/RDM containing neomycin, rifampicin, and Calcofluor. Screening for mTn5 insertions in genes involved in EPS production was achieved by observing nonmucoid colonies and fluorescence under UV light.

IDM for R7AexoK, R7AexoO, R7Amlr5265, and R7A mlr5266 were constructed using the suicide vector pFUS2 (Antoine et al. 2000). Primer pairs were designed to PCRamplify approximately 350-bp internal fragments of the target genes that were then cloned into pFUS2. Constructs were transformed into S17-1/ $\lambda$ pir (Herrero et al. 1990), then transferred into R7A by biparental spot matings. Exconjugants were passaged four times on G/RDM containing gentamicin. Mutants were confirmed by sequencing and Southern hybridization.

In-frame markerless deletion mutants R7A $\Delta$ exoA and $\mathrm{R} 7 \mathrm{~A} \Delta \mathrm{ndvB}$ were constructed through allelic replacement of the wild-type gene with a mutated form containing an in-frame markerless internal deletion through homologous recombination, as previously described (Rodpothong et al. 2009).

\section{Reporter plasmid construction.}

GFP expressed from the $n p t$ II promoter (PnptII) was PCRamplified as a fragment of approximately $1.1 \mathrm{~kb}$ from pPR3 (Rodpothong et al. 2009) using primers nptIIL1 (AAATTTAA GCTTCACGCTGCCGCAAGCACTCA) and PnptIIgfpR1 (ATATATGATATCGATGCCTGGAATTAATTC) that incorporated HindIII and EcoRV restriction sites, respectively. The PCR fragment was cloned into pFAJ1700 that had been digested with HindIII and HpaI to form pSKGFP

Primers 1708DsRedL (ATATATGGATCCTGACTAGCTAA AGGAGAGAAAAGTATGGCCTCCTCCGAGGACGT) and 1708DsRedR (AAATTTGAATTCCTACAGGAACAGGTGG TGGC) were used to amplify the dsred gene from pDsRedExpress-N1 (Clonetech, Palo Alto, CA, U.S.A.) with BamHI and EcoRI restriction sites incorporated, respectively. Primer 1708DsRedL incorporated the ribosome binding site of a strongly expressed R7A gene (msil58) to ensure strong expression of the gene in R7A strains. The plasmid pFAJ1708 encodes PnptII upstream of the multiple cloning site; therefore, the 714-bp DsRed PCR product was cloned into the MCS of pFAJ1708 as a BamHI/EcoRI fragment to form pSKDSRED.

\section{Plant assays.}

Seed were prepared as described previously (Rodpothong et al. 2009). For nodulation assays, germinated seedlings were transferred to individual foam-capped 15 -mm test tubes containing 8-ml slants of Jensen's seedling agar (Vincent 1970) and grown for $48 \mathrm{~h}$ prior to inoculation with G/RDM plate culture resuspended in sterile water. Plants were observed periodically over 6 weeks, with each assay consisting of at least 10 plants per strain and repeated three times. For IT and co-inoculation assays, seedlings were transferred to square petri dishes (10 by $10 \mathrm{~cm}$ ) containing $50-\mathrm{ml}$ slants of Jensen's seedling agar. Bacterial growth from fresh G/RDM plates supplemented with appropriate antibiotics was resuspended in sterile water and suspensions were adjusted to an optical density at $600 \mathrm{~nm}$ of 0.1 . Each seedling was inoculated with $50 \mu \mathrm{l}$. For co-inoculation assays, plate-count methods were carried out to verify an inoculation ratio of $1: 1$. Unless otherwise stated, plants were grown at $70 \%$ humidity with temperature maintained at $25^{\circ} \mathrm{C}$ during the day and $14^{\circ} \mathrm{C}$ at night on a cycle of $16 \mathrm{~h}$ per day and $8 \mathrm{~h}$ per night. Under the normal plant growth conditions used, the roots of the plants were exposed to the overhead light. For experiments in which plant roots were kept in the dark, the plant plates were fitted into a blackened-out container that resulted in only the shoots being exposed to the light.

\section{Microscopy.}

Roots from seedlings inoculated with R7ALZ and R7Aexo ULZ were removed 10 to $14 \mathrm{dpi}$ and fixed and stained as described (Boivin et al. 1990; Walker and Downie 2000), mounted on slides in sterile water, and viewed using an Olympus BX51 microscope. To visualize DsRed- and GFP-expressing cells within IT, seedling roots were mounted on slides in sterile water and viewed using an Olympus BX51 microscope with fluorescence illuminator (BX-RFA) at 7 to 14 dpi. GFP-expressing cells were visualized with fluorescence mirror unit model U-MWIB3 and DsRed-expressing cells were visualized using fluorescence mirror unit model U-MWIG3. Confocal microscopy of nodules was performed using a Zeiss LSM 510 upright confocal microscope, with excitation at $488 \mathrm{~nm}$ for GFP and $568 \mathrm{~nm}$ for DsRed and a BP505-530 emission filter for GFP and a LP585 filter for DsRed. Images were recorded with LSM image browser software.

\section{EPS extraction.}

$\mathrm{G} / \mathrm{RDM}$ broths $(5 \mathrm{ml})$ of $M$. loti strains grown at $28^{\circ} \mathrm{C}$ for $48 \mathrm{~h}$ were used to seed $800-\mathrm{ml}$ G/RDM broths in 2-liter baffled flasks that were grown at $28^{\circ} \mathrm{C}$ with shaking for $72 \mathrm{~h}$. Cells were pelleted by centrifugation at $5930 \mathrm{~g}$ for $20 \mathrm{~min}$ at $4{ }^{\circ} \mathrm{C}$ with the supernatant recovered and concentrated down to a volume of approximately $100 \mathrm{ml}$ by rotary evaporation. Concentrated supernatant was again centrifuged at $5,930 \times g$ for 20 $\min$ at $4{ }^{\circ} \mathrm{C}$ to remove any remaining contaminants. Three volumes $(300 \mathrm{ml})$ of absolute ethanol were added to the supernatant and the mixture left to stand at $4{ }^{\circ} \mathrm{C}$ for $4 \mathrm{~h}$. Precipitated EPS was then recovered by centrifugation at $5,930 \times g$ for 20 min at $4^{\circ} \mathrm{C}$ and resuspended in 20 to $30 \mathrm{ml}$ of Milli-Q water. The suspension was transferred to dialysis tubing $(6,000 \mathrm{Da}$ molecular weight cut-off [MWCO]) that had been prepared by autoclaving in a $2 \%$ sodium bicarbonate solution and rinsed in Milli-Q water. The EPS extract was dialyzed against several changes of Milli-Q water over a 24-h period. Extract was then transferred to Falcon tubes in 15-ml aliquots, snap frozen in a dry ice/ethanol bath, and lyophilized for $48 \mathrm{~h}$. 


\section{Gel permeation chromatography.}

Crude EPS extract $(10 \mathrm{mg})$ was suspended in $1 \mathrm{ml}$ of degassed filter-sterile Milli-Q water and placed in an ultrasonic bath for $10 \mathrm{~min}$. For each run, the Sephacryl S-400 column (120 by $1.5 \mathrm{~cm}$ internal diameter [i.d.]) was charged with $5 \mathrm{mg}$ of the EPS and elution was monitored with a refractive index detector. Fractions were collected with a Spectra Chrom Fraction Collector CF-2 (15 min/tube). At the conclusion of each run, fractions representing HMW EPS or LMW polysaccharides were pooled based on refractive index reading and lyophilized to recover the EPS.

\section{Trimethylsilyl derivatization of EPS samples.}

To identify the glycosyl residues present in the EPS preparations, TMS derivatives were prepared as described by York and associates (1985). Samples were methanolyzed with $1 \mathrm{M} \mathrm{HCL}$ in $\mathrm{MeOH}$ at $80^{\circ} \mathrm{C}$ for $18 \mathrm{~h}$, then re-N-acetylated in the presence of $\mathrm{MeOH} / \mathrm{Ac}_{2} \mathrm{O} /$ pyridine $\left(2 / 1 / 1\right.$ by volume) at $100^{\circ} \mathrm{C}$ for $1 \mathrm{~h}$. Following evaporation, Tri-Sil reagent was added to samples that were then incubated at $80^{\circ} \mathrm{C}$ for $30 \mathrm{~min}$. The TMS derivatives were analyzed on a Hewlett-Packard HP5890 gas chromatograph equipped with a mass selective detector 5970 using an Alltech AT-1 fused silica capillary column ( $30 \mathrm{~m}$ by $0.25 \mathrm{~mm}$ i.d.). Helium was used as the carrier gas. Initial oven temperature was $80^{\circ} \mathrm{C}$ for $2 \mathrm{~min}$, then ramped to $160^{\circ} \mathrm{C}$ at $20^{\circ} \mathrm{C} / \mathrm{min}$, with a 2-min hold. This was followed by a ramp to $200^{\circ} \mathrm{C}$ at $2^{\circ} \mathrm{C} / \mathrm{min}$ followed by an increase to $250^{\circ} \mathrm{C}$ at $10^{\circ} \mathrm{C} / \mathrm{min}$, with an 11-min hold. The results were processed and interpreted using The Standard Chemstation software (ver. A.03.00).

\section{Determination of uronic acids with pre-reduction of carboxyl groups.}

To determine the presence of uronic acids, EPS samples were methyl esterified with $0.5 \mathrm{M} \mathrm{HCl}-\mathrm{MeOH}$ at $80^{\circ} \mathrm{C}$ for 30 min followed by reduction with $\mathrm{NaBD}_{4}$ at neutral $\mathrm{pH}$ for $2 \mathrm{~h}$. After reduction, borate was removed by extensive evaporations using 90\% (vol/vol) acetic acid in $\mathrm{MeOH}$. Any remaining salts were removed by $48 \mathrm{~h}$ of dialysis (100 to $500 \mathrm{Da}$ MWCO) against several changes of distilled water. The resulting carboxyl-reduced EPS samples were hydrolyzed with $2 \mathrm{M}$ trifluoroacetic acid at $121^{\circ} \mathrm{C}$ for $2 \mathrm{~h}$ and converted to AA as described by York and associates (1985). Samples were then extracted five times in dichloromethane and, after reducing volume to $40 \mu \mathrm{l}, 1 \mu \mathrm{l}$ was analyzed on a Hewlett-Packard HP5890 gas chromatograph equipped with a mass selective detector 5970 MSD using a Supelco-SP-2330 Capillary GC Column (30 $\mathrm{m}$ by $0.25 \mathrm{~mm}$ i.d.). GC/MS analysis was performed using both electron ionization and chemical ionization fragmentation. Glycose identification was accomplished using AA prepared from authentic standards

\section{ACKNOWLEDGMENTS}

This work was funded by grants to J. Stougaard from the Danish National Research Foundation and the European Research Council, and to the CCRC from the DOE (DE-FG02-93ER20097). S. J. Kelly and A. M. Hubber thank the University of Otago for Ph.D. scholarships. All authors were involved in the design of the research; S. J. Kelly, A. M. Hubber, A. Muszyński, Y. Kawaharada, N. Sandal, and J. T. Sullivan performed the research; all authors were involved in data analysis and interpretation; S. J. Kelly and C. W. Ronson drafted the manuscript; and all authors were involved in revising the manuscript and approved the final version.

\section{LITERATURE CITED}

Aman, P., Franzen, L. E., Darvill, J. E., and Albersheim, P. 1982. Structural elucidation, using HPLC-MS and GLC-MS of the acidic polysac- charide secreted by Rhizobium meliloti strain 1021. Carbohydr. Res. 95:263-282.

Amemura, A., Hisamatsu, M., Ghai, S. K., and Harada, T. 1981. Structural studies on a new polysaccharide, containing D-riburonic acid, from Rhizobium meliloti IFO13336. Carbohydr. Res. 91:59-65.

Antoine, R., Alonso, S., Raze, D., Coutte, L., Lesjean, S., Willery, E. Locht, C., and Jacob-Dubuisson, F. 2000. New virulence-activated and virulence-repressed genes identified by systematic gene inactivation and generation of transcriptional fusions in Bordetella pertussis. J. Bacteriol. 182:5902-5905.

Battisti, L., Lara, J. C., and Leigh, J. A. 1992. Specific oligosaccharide form of the Rhizobium meliloti exopolysaccharide promotes nodule invasion in alfalfa. Proc. Natl. Acad. Sci. U.S.A. 89:5625-5629.

Becker, A., Kleickmann, A., Kuster, H., Keller, M., Arnold, W., and Puhler, A. 1993. Analysis of the Rhizobium meliloti genes exoU, exoV, exoW, exoT, and exoI involved in exopolysaccharide biosynthesis and nodule invasion: exoU and exoW probably encode glucosyltransferases. Mol. Plant-Microbe Interact. 6:735-744.

Becker, A., Niehaus, K., and Puhler, A. 2000. The role of rhizobial extracellular polysaccharides (EPS) in the Sinorhizobium meliloti-alfalfa symbiosis. Pages 443-448 in: Prokaryotic Nitrogen Fixation: A Model System for the Analysis of a Biological process. E. W. Triplett, ed. Horizon Scientific Press, Wymondham, U.K.

Becker, A., Fraysse, N., and Sharypova, L. 2005. Recent advances in studes on structure and symbiosis-related function of rhizobial K-antigens and lipopolysaccharides. Mol. Plant-Microbe Interact. 18:899905.

Beringer, J. E. 1974. R factor transfer in Rhizobium leguminosarum. J. Gen. Microbiol. 84:188-198.

Boivin, C., Camut, S., Malpica, C. A., Truchet, G., and Rosenberg, C. 1990. Rhizobium meliloti genes encoding catabolism of trigonelline are induced under symbiotic conditions. Plant Cell 2:1157-1170.

Canter Cremers, H. C., Batley, M., Redmond, J. W., Eydems, L., Breedveld, M. W., Zevehuizen, L. P., Pees, E., Wijffelman, C. A., and Lugtenberg, B. J. 1990. Rhizobium leguminosarum exoB mutants are deficient in the synthesis of UDP-glucose $4^{\prime}$-epimerase. J. Biol. Chem. 265:21122-21127.

Cheng, H. P., and Walker, G. C. 1998. Succinoglycan is required for initiation and elongation of infection threads during nodulation of alfalfa by Rhizobium meliloti. J. Bacteriol. 180:5183-5191.

Desbrosses, G. J., and Stougaard, J. 2011. Root nodulation: A paradigm for how plant-microbe symbiosis influences host developmental pathways. Cell Host Microbe 10:348-358.

Djordjevic, S. P., Chen, H., Batley, M., Redmond, J. W., and Rolfe, B. G. 1987. Nitrogen fixation ability of exopolysaccharide synthesis mutants of Rhizobium sp. strain NGR234 and Rhizobium trifolii is restored by the addition of homologous exopolysaccharides. J. Bacteriol. 169:53-60.

Dombrecht, B., Vanderleyden, J., and Michiels, J. 2001. Stable RK2derived cloning vectors for the analysis of gene expression and gene function in gram-negative bacteria. Mol. Plant-Microbe Interact. 14:426-430.

Finan, T. M., Hirsch, A. M., Leigh, J. A., Johansen, E., Kuldau, G. A., Deegan, S., Walker, G. C., and Signer, E. R. 1985. Symbiotic mutants of Rhizobium meliloti that uncouple plant from bacterial differentiation. Cell 40:869-877.

Finan, T. M., Weidner, S., Wong, K., Buhrmester, J., Chain, P., Vorhoelter, F. J., Hernandez-Lucas, I., Becker, A., Cowie, A., Gouzy, J., Golding, B., and Puehler, A. 2001. The complete sequence of the 1,683-kb pSymB megaplasmid from the N2-fixing endosymbiont Sinorhizobium meliloti. Proc. Natl. Acad. Sci. U.S.A. 98:9889-9894.

Fraysse, N., Couderc, F., and Poinsot, V. 2003. Surface polysaccharide involvement in establishing the rhizobium-legume symbiosis. Eur. J. Biochem. 270:1365-1380.

Gage, D. J. 2004. Infection and invasion of roots by symbiotic, nitrogenfixing rhizobia during nodulation of temperate legumes. Microbiol. Mol. Biol. Rev. 68:280-300.

Glucksmann, M. A., Reuber, T. L., and Walker, G. C. 1993. Family of glycosyl transferases needed for the synthesis of succinoglycan by Rhizobium meliloti. J. Bacteriol. 175:7033-7044.

Gonzalez, J. E., York, G. M., and Walker, G. C. 1996. Rhizobium meliloti exopolysaccharides: Synthesis and symbiotic function. Gene 179:141146.

Herrero, M., de Lorenzo, V., and Timmis, K. N. 1990. Transposon vectors containing non-antibiotic resistance selection markers for cloning and stable chromosomal insertion of foreign genes in gram-negative bacteria. J. Bacteriol. 172:6557-6567.

Hisamatsu, M., Nomura, S., Shutsrirung, A., Obata, H., Teranishi, K., Yamada, T., Nuswantara, S., Yamashita, M., and Murooka, Y. 1997. Structural characterization of a new acidic exopolysaccharide and cy- 
clic $(1 \rightarrow 2) \beta$-glucan produced by Rhizobium huakuii forming nodules on Astragalus sinicus. J. Ferment. Bioeng. 83:315-320.

Hotter, G. S., and Scott, D. B. 1991. Exopolysaccharide mutants of Rhizobium loti are fully effective on a determinate nodulating host but are ineffective on an indeterminate nodulating host. J. Bacteriol. 173:851-859.

Jones, K. M., Kobayashi, H., Davies, B. W., Taga, M. E., and Walker, G. C. 2007. How rhizobial symbionts invade plants: The SinorhizobiumMedicago model. Nat. Rev. Microbiol. 5:619-633.

Kaneko, T., Nakamura, Y., Sato, S., Asamizu, E., Kato, T., Sasamoto, S., Watanabe, A., Idesawa, K., Ishikawa, A., Kawashima, K., Kimura, T., Kishida, Y., Kiyokawa, C., Kohara, M., Matsumoto, M., Matsuno, A., Mochizuki, Y., Nakayama, S., Nakazaki, N., Shimpo, S., Sugimoto, M., Takeuchi, C., Yamada, M., and Tabata, S. 2000. Complete genome structure of the nitrogen-fixing symbiotic bacterium Mesorhizobium loti. DNA Res. 7:331-338.

Kim, C. H., Tully, R. E., and Keister, D. L. 1989. Exopolysaccharide-deficient mutants of Rhizobium fredii $\mathrm{HH} 303$ which are symbiotically effective. Appl. Environ. Microbiol. 55:1852-1854.

Ko, Y. F., and Gayda, R. 1990. Nodule formation in soybeans by exopolysaccharide mutants of Rhizobium fredii USDA191. J. Gen. Microbiol. 136:105-113

Laus, M. C., Logman, T. J., Van Brussel, A. A., Carlson, R. W., Azadi, P., Gao, M. Y., and Kijne, J. W. 2004. Involvement of exo5 in production of surface polysaccharides in Rhizobium leguminosarum and its role in nodulation of Vicia sativa subsp. nigra. J. Bacteriol. 186:6617-6625.

Laus, M. C., van Brussel, A. A., and Kijne, J. W. 2005. Role of cellulose fibrils and exopolysaccharides of Rhizobium leguminosarum in attachment to and infection of Vicia sativa root hairs. Mol. Plant-Microbe Interact. 18:533-538.

Leigh, J. A., Signer, E. R., and Walker, G. C. 1985. Exopolysaccharidedeficient mutants of Rhizobium meliloti that form ineffective nodules. Proc. Natl. Acad. Sci. U.S.A. 82:6231-6235.

Leong, S. A., Williams, P. H., and Ditta, G. S. 1985. Analysis of the $5^{\prime}$ regulatory region of the gene for delta-aminolevulinic acid synthetase of Rhizobium meliloti. Nucleic Acids Res. 13:5965-5976.

Long, S. R. 1996. Rhizobium symbiosis: Nod factors in perspective. Plant Cell 8:1885-1898.

Long, S., Reed, J. W., Himawan, J., and Walker, G. C. 1988. Genetic analysis of a cluster of genes required for synthesis of the Calcofluorbinding exopolysaccharide of Rhizobium meliloti. J. Bacteriol. 170:4239-4248.

Michiels, K. W., Vanderleyden, J., Van Gool, A. P., and Signer, E. R. 1988. Isolation and characterization of Azospirillum brasilense loci that correct Rhizobium meliloti exoB and exoC mutations. J. Bacteriol. 170:5401-5404

Murakami, E., Nagata, M., Shimoda, Y., Kucho, K., Higashi, S., Abe, M., Hashimoto, M., and Uchiumi, T. 2011. Nitric oxide production induced in roots of Lotus japonicus by lipopolysaccharide from Mesorhizobium loti. Plant Cell Physiol. 52:610-617.

Nagata, M., Murakami, E., Shimoda, Y., Shimoda-Sasakura, F., Kucho, K., Suzuki, A., Abe, M., Higashi, S., and Uchiumi, T. 2008. Expression of a class 1 hemoglobin gene and production of nitric oxide in response to symbiotic and pathogenic bacteria in Lotus japonicus. Mol. PlantMicrobe Interact. 21:1175-1183.

Niehaus, K., Kapp, D., and Puhler, A. 1993. Plant defense and delayed infection of alfalfa pseudonodules induced by an exopolysaccharide (EPS I)-deficient Rhizobium meliloti mutant. Planta 190:415-425.

Oldroyd, G. E. D., Murray, J. D., Poole, P. S., and Downie, J. A. 2011. The rules of engagement in the legume-rhizobial symbiosis. Annu. Rev. Genet. 45:119-144.

Parniske, M., Schmidt, P. E., Kosch, K., and Muller, P. 1994. Plant defense responses of host plants with determinate nodules induced by EPS-defective exoB mutants of Bradyrhizobium japonicum. Mol. PlantMicrobe Interact. 7:631-638.

Pellock, B. J., Cheng, H. P., and Walker, G. C. 2000. Alfalfa root nodule invasion efficiency is dependent on Sinorhizobium meliloti polysaccharides. J. Bacteriol. 182:4310-4318.

Perret, X., Staehelin, C., and Broughton, W. J. 2000. Molecular basis of symbiotic promiscuity. Microbiol. Mol. Biol. Rev. 64:180-201.

Quandt, J., and Hynes, M. F. 1993. Versatile suicide vectors which allow direct selection for gene replacement in gram-negative bacteria. Gene 127:15-21.

Reeve, W. G., Tiwari, R. P., Worsley, P. S., Dilworth, M. J., Glenn, A. R., and Howieson, J. G. 1999. Constructs for insertional mutagenesis, transcriptional signal localization and gene regulation studies in root nodule and other bacteria. Microbiology 145:1307-1316.

Reinhold, B. B., Chan, S. Y., Reuber, T. L., Marra, A., Walker, G. C., and Reinhold, V. N. 1994. Detailed structural characterization of succinoglycan, the major exopolysaccharide of Rhizobium meliloti Rm1021. J. Bacteriol. 176:1997-2002.

Reuber, T. L., and Walker, G. C. 1993. Biosynthesis of succinoglycan, a symbiotically important exopolysaccharide of Rhizobium meliloti. Cell 74:269-280.

Rodpothong, P., Sullivan, J. T., Songsrirote, K., Sumpton, D., Cheung, K. W., Thomas-Oates, J., Radutoiu, S., Stougaard, J., and Ronson, C. W. 2009. Nodulation gene mutants of Mesorhizobium loti R7A nodZ and nolL mutants have host-specific phenotypes on Lotus spp. Mol. PlantMicrobe Interact. 22:1546-1554.

Ronson, C. W., Nixon, B. T., Albright, L. M., and Ausubel, F. M. 1987. Rhizobium meliloti ntrA (rpoN) gene is required for diverse metabolic functions. J. Bacteriol. 169:2424-2431.

Russa, R., Urbanik-Sypniewska, T., Lindstrom, K., and Mayer, H. 1995. Chemical characterization of two lipopolysaccharide species isolated from Rhizobium loti NZP2213. Arch. Microbiol. 163:345-351.

Sanchez-Andujar, B., Coronado, C., Philip-Hollingsworth, S., Dazzo, F. B., and Palomares, A. J. 1997. Structure and role in symbiosis of the exoB gene of Rhizobium leguminosarum bv. trifolii. Mol. Gen. Genet. $255: 131-140$

Skorupska, A., Janczarek, M., Marczak, M., Mazur, A., and Krol, J. 2006. Rhizobial exopolysaccharides: Genetic control and symbiotic functions. Microb. Cell Fact 5:7-26.

Staehelin, C., Forsberg, L. S., D'Haeze, W., and other authors 2006. Exooligosaccharides of Rhizobium sp. strain NGR234 are required for symbiosis with various legumes. J. Bacteriol. 188:6168-6178.

Streit, W. R., Schmitz, R. A., Perret, X., Staehelin, C., Deakin, W. J., Raasch, C., Liesegang, H., and Broughton, W. J. 2004. An evolutionary hot spot: The pNGR234b replicon of Rhizobium sp. strain NGR234. J. Bacteriol. 186:535-542.

Stuurman, N., Pacios Bras, C., Schlaman, H. R., Wijfjes, A. H., Bloemberg, G., and Spaink, H. P. 2000. Use of green fluorescent protein color variants expressed on stable broad-host-range vectors to visualize rhizobia interacting with plants. Mol. Plant-Microbe Interact. 13:1163-1169.

Sullivan, J. T., Trzebiatowski, J. R., Cruickshank, R. W., and other authors 2002. Comparative sequence analysis of the symbiosis island of Mesorhizobium loti strain R7A. J. Bacteriol. 184:3086-3095.

Urzainqui, A., and Walker, G. C. 1992. Exogenous suppression of the symbiotic deficiencies of Rhizobium meliloti exo mutants. J. Bacteriol 174:3403-3406.

Vincent, J. M. 1970. A Manual for the Practical Study of Root-Nodule Bacteria. Blackwell Scientific Publications, Oxford.

Walker, S. A., and Downie, J. A. 2000. Entry of Rhizobium leguminosarum bv. viciae into root hairs requires minimal Nod factor specificity, but subsequent infection thread growth requires nodO or nodE. Mol. PlantMicrobe Interact. 13:754-762.

Wang, L. X., Wang, Y., Pellock, B., and Walker, G. C. 1999. Structural characterization of the symbiotically important low-molecular-weight succinoglycan of Sinorhizobium meliloti. J. Bacteriol. 181:6788-6796.

Wielbo, J., Mazur, A., Krol, J., Marczak, M., Kutkowska, J., and Skorupska, A. 2004. Complexity of phenotypes and symbiotic behaviour of Rhizobium leguminosarum biovar trifolii exopolysaccharide mutants. Arch. Microbiol. 182:331-336.

York, G. M. and Walker, G. C. 1998. The Rhizobium meliloti ExoK and ExsH glycanases specifically depolymerize nascent succinoglycan chains. Proc. Natl. Acad. Sci. U.S.A. 95:4912-4917.

York, W. S., Darvill, A. G., McNeil, M., Stevenson, T. T., and Albersheim, P. 1985. Isolation and characterization of plant-cell walls and cell-wall components. Methods Enzymol. 118:3-40.

Zhan, H. J., Gray, J. X., Levery, S. B., Rolfe, B. G., and Leigh, J. A. 1990. Functional and evolutionary relatedness of genes for exopolysaccharide synthesis in Rhizobium meliloti and Rhizobium sp. strain NGR234. J. Bacteriol. 172:5245-5253. 